\title{
Influence of 1D and 2D Carbon Fillers and Their Functionalisation on Crystallisation and Thermomechanical Properties of Injection Moulded Nylon 6,6 Nanocomposites
}

\author{
Fabiola Navarro-Pardo, ${ }^{1,2,3}$ Ana L. Martínez-Hernández, ${ }^{2,3}$ \\ Victor M. Castaño, ${ }^{2}$ José L. Rivera-Armenta, ${ }^{4}$ Francisco J. Medellín-Rodríguez, ${ }^{5}$ \\ Gonzalo Martínez-Barrera, ${ }^{6}$ and Carlos Velasco-Santos ${ }^{2,3}$ \\ ${ }^{1}$ Facultad de Química, Universidad Autónoma del Estado de México, Posgrado en Ciencia de Materiales, \\ Km. 12 de la Carretera Toluca-Atlacomulco, 50200 San Cayetano, Toluca, MEX, Mexico \\ ${ }^{2}$ Centro de Física Aplicada y Tecnología Avanzada, Universidad Nacional Autónoma de México, Boulevard Juriquilla No. 3001, \\ Juriquilla, 76230 Santiago de Querétaro, QRO, Mexico \\ ${ }^{3}$ Instituto Tecnológico de Querétaro, División de Estudios de Posgrado e Investigación, Avenida Tecnológico s/n, \\ Esquina Gral. Mariano Escobedo, Colonia Centro Histórico, 76000 Santiago de Querétaro, QRO, Mexico \\ ${ }^{4}$ Instituto Tecnológico de Ciudad Madero, División de Estudios de Posgrado e Investigación, Juventino Rosas y Jesús Urueta, \\ Colonia Los Mangos, 89440 Ciudad Madero, TAMPS, Mexico \\ ${ }^{5}$ Universidad Autónoma del San Luis Potosí, Facultad de Ciencias Químicas, Avenida Manuel Nava 6, Zona Universitaria, \\ 78210 San Luis Potosí, SLP, Mexico \\ ${ }^{6}$ Facultad de Química, Universidad Autónoma del Estado de México, Laboratorio de Investigación y Desarrollo de Materiales \\ Avanzados, Km. 12 de la Carretera Toluca-Atlacomulco, 50200 San Cayetano, Toluca, MEX, Mexico
}

Correspondence should be addressed to Carlos Velasco-Santos; cylaura@gmail.com

Received 15 February 2014; Revised 21 June 2014; Accepted 23 June 2014; Published 22 July 2014

Academic Editor: Jinlong Jiang

Copyright (C) 2014 Fabiola Navarro-Pardo et al. This is an open access article distributed under the Creative Commons Attribution License, which permits unrestricted use, distribution, and reproduction in any medium, provided the original work is properly cited.

Carbon nanotubes (CNTs) and graphene were used as reinforcing fillers in nylon 6,6 in order to obtain nanocomposites by using an injection moulding process. The two differently structured nanofillers were used in their pristine or reduced form, after oxidation treatment and after amino functionalisation. Three low nanofiller contents were employed. Crystallisation behaviour and perfection of nylon 6,6 crystals were determined by differential scanning calorimetry and wide angle X-ray diffraction, respectively. Crystallinity was slightly enhanced in most samples as the content of the nanofillers was increased. The dimensionality of the materials was found to provide different interfaces and therefore different features in the nylon 6,6 crystal growth resulting in improved crystal perfection. Dynamical, mechanical analysis showed the maximum increases provided by the two nanostructures correspond to the addition of $0.1 \mathrm{wt} . \%$ amino functionalised CNTs, enhancing in 30\% the storage modulus and the incorporation of 0.5 wt. \% of graphene oxide caused an increase of $44 \%$ in this property. The latter also provided better thermal stability when compared to pure nylon 6,6 under inert conditions. The superior properties of graphene nanocomposites were attributed to the larger surface area of the two-dimensional graphene compared to the one-dimensional CNTs.

\section{Introduction}

Carbon nanotubes (CNTs) and graphene have raised great interest because of their unique physical, chemical, and mechanical properties [1-5]. A variety of polymer nanocomposites employing these nanomaterials have been developed and these works have shown promising results in this field of application [6-12]. Despite the great potential of both carbon allotropes for their use as nanofillers, dispersion and strong interfacial adhesion between the nanofiller and the matrix remain the key challenge for effective reinforcement of polymers [8, 9, 12-14]. Extensive research has been made on 
the chemical functionalisation of these carbon nanomaterials [7-14]. The modifications imparted to these nanomaterials dictate their properties and therefore have an impact on the nanocomposites obtained from them [15-17]. Functionalisation of these nanomaterials prevents their aggregation and improves their dispersion in polymer matrices resulting in efficient stress transfer between both phases $[9,13]$. Functional groups at the surface of CNTs or graphene make the strongest interfacial interactions with the polymer matrix $[7,8,11]$. The use of polymers with functional groups in their monomer units also favours these aspects; nylon 6,6 contains amide groups separated by methylene units in its structure. The ordered array of polymer chains packed due to hydrogen bonding and the subsequent folding of these chains into sheets due to Van der Waals forces provide a degree of crystallinity to this polyamide [18]. Furthermore, several studies have shown that the addition of a second phase in polymer matrices modifies the crystallisation behaviour of polymers [8-10, 16-19]. Additionally, it is well known that the properties of semicrystalline polymers are strongly dependent on their crystalline structure [7-9].

CNTs dominate the research among carbon based materials used as reinforcing agents in polymers. On the other hand, graphene based nanocomposites have been gaining more importance because of the superior properties of this nanofiller. Only a few works have shown the influence between both differently dimensional structures on the crystallisation behaviour or the mechanical properties of polymers [17, 20-22]. Lamastra et al. [21] reinforced poly $(\varepsilon-$ caprolactone) with electrospun poly(methyl methacrylate) (PMMA) fibres containing CNTs and graphene nanoplatelets. The nanocomposites reinforced with wellexfoliated graphene sheets showed the best results in the mechanical properties providing an increase of $180 \%$ in yield strength when compared to the pure matrix. Chatterjee et al. [22] reinforced nylon 12 spun fibres with both carbon nanofillers; CNTs and graphene favoured the increase in the equatorial percentage crystallinity of nylon 12 and graphene showed to be the best reinforcing filler with an improvement of $400 \%$ in elastic modulus. Recent works concerning the influence provided by both carbon structures on crystallisation and thermomechanical properties have been based on pristine materials [20-23]. Our research group has investigated these effects on electrospun nanocomposites containing functionalised $1 \mathrm{D}$ and $2 \mathrm{D}$ carbon fillers, showing the differences between both carbon nanomaterials $[7,8]$.

Injection moulding is a very important technique for industrial purposes, because it is a fast and an automated process for large scale manufacture of complex products at minimum cost. Injection moulded automotive parts reinforced with CNTs or graphene could be a potential application of the type of nanocomposites developed in this work. Comprehensive understanding of both carbon nanostructures is needed in order to optimise the processing conditions in industrial processes and achieve desirable properties. The aim of this work is to investigate the influence of one-dimensional (1D) and two-dimensional (2D) structures of carbon on the crystallisation and the thermomechanical properties of nylon 6,6 nanocomposites obtained by the injection moulding process using different nanofiller contents. The effect that functionalisation provides to the properties mentioned above is also presented.

\section{Materials and Methods}

Chemical vapour deposition multiwalled carbon nanotubes (Sunnano Company), with $10-30 \mathrm{~nm}$ in outer diameter, 1$10 \mu \mathrm{m}$ length, and purity above $80 \%$, were refluxed for three hours at $80^{\circ} \mathrm{C}$ in a $3: 1$ molar solution of nitric acid $\left(\mathrm{HNO}_{3}, 70 \%\right.$, Sigma-Aldrich) and sulphuric acid $\left(\mathrm{H}_{2} \mathrm{SO}_{4}\right.$, $98 \%$, J. T. Baker). The solution was filtered and washed with distilled water until achieving neutral $\mathrm{pH}$. Finally, the oxidised carbon nanotubes (OCNT) were dried overnight at $80^{\circ} \mathrm{C}[8]$.

Graphene oxide (GO) was obtained from graphite using the modified Hummers method [1], in which $23 \mathrm{~mL}$ of $\mathrm{H}_{2} \mathrm{SO}_{4}$ was added into a reaction flask submerged in an ice bath and kept there until it reached $0^{\circ} \mathrm{C}$. $1 \mathrm{~g}$ graphite (Number 70230, Electron Microscopy Science) and $3 \mathrm{~g}$ potassium permanganate $\left(\mathrm{KMnO}_{4}\right.$, Merck) were added slowly followed by stirring at $35^{\circ} \mathrm{C}$ for two hours and then diluted with $46 \mathrm{~mL}$ of distilled water for 15 minutes under stirring. After that, a solution of $5 \mathrm{~mL}$ of hydrogen peroxide $\left(\mathrm{H}_{2} \mathrm{O}_{2}, 30 \%\right.$, J.T. Baker) in $135 \mathrm{~mL}$ of distilled water was added to reduce residual $\mathrm{KMnO}_{4}$. A solution of $2.5 \mathrm{~mL}$ hydrochloric acid $(\mathrm{HCl}$, $37 \%$, Sigma-Aldrich) in $100 \mathrm{~mL}$ of distilled water was added to remove metal ions followed by filtration with excess water to remove acid. Finally, the graphite oxide was dried overnight at $60^{\circ} \mathrm{C}$. In order to obtain $\mathrm{GO}, 0.5 \mathrm{~g}$ of graphite oxide (batches of $100 \mathrm{mg}$ ) was redispersed into water $(10 \mathrm{~mL}$ per batch) for being exfoliated using sonication for three hours in an ultrasound bath (Autoscience 10200B, at a frequency of $40 \mathrm{~Hz}$ ); the resulting $\mathrm{GO}$ dispersion was filtrated and dried overnight at $60^{\circ} \mathrm{C}$. Reduced graphene oxide (RGO) was obtained by adding $0.25 \mathrm{~g}$ Hexamethylenetetramine (HMTA, Sigma-Aldrich) to $0.25 \mathrm{~g}$ GO dispersed in water and kept under stirring at $100^{\circ} \mathrm{C}$ for 10 hours [2]. The RGO was filtered and washed with distilled water until reaching neutral $\mathrm{pH}$ and dried overnight at $60^{\circ} \mathrm{C}$.

An acid-base titration with sodium hydroxide $(\mathrm{NaOH}$, $98 \%$, Sigma-Aldrich) was used to determine the concentration of acidic surface groups [3]. The oxidised carbon materials were added into $25 \mathrm{~mL}$ of a $0.04 \mathrm{~N} \mathrm{NaOH}$ solution and stirred for $48 \mathrm{~h}$ to allow the acidic groups on the nanomaterials to neutralise with the basic solution. The mixture was titrated with a $0.04 \mathrm{~N} \mathrm{HCl}$ solution to determine the excess $\mathrm{NaOH}$ in the solution and the concentration of the carboxylates on OCNT and GO. The concentrations of acidic surface sites were $6.5 \mathrm{mmol} / \mathrm{g}$ in OCNT and $5.4 \mathrm{mmol} / \mathrm{g}$ in GO. The nanomaterials were functionalised as follows: a 1:1 molar ratio solution of carbon nanomaterial and 1-ethyl-3-[3dimethylaminopropyl] carbodiimide hydrochloride) (EDAC, $99 \%$, Sigma-Aldrich) was kept under stirring at $80^{\circ} \mathrm{C}$ in dimethylamine excess for $6 \mathrm{~h}$. The material obtained was washed until neutral $\mathrm{pH}$ and dried overnight at $60^{\circ} \mathrm{C}$. The functionalised carbon nanotubes and graphene were labelled as $\mathrm{f}-\mathrm{CNT}$ and $\mathrm{f}-\mathrm{Ge}$, respectively. 
Nylon 6,6 (Ultramid A3K, BASF) was dried at $60^{\circ} \mathrm{C}$ for 12 hours. Prior to injection moulding, the pellets were mixed with the carbon nanofillers and agitated so that the charged particles are deposited on the surface of nylon pellets due to electrostatic forces. Three nanofiller contents were chosen: $0.1,0.3$, and $0.5 \mathrm{wt} . \%$. The mixed blends were moulded into a $50 \times 44 \times 2 \mathrm{~mm}^{3}$ aluminium mould by an injection machine (AB-200, AB Machinery) at a moulding temperature of $270^{\circ} \mathrm{C}$ and pressure of 110 psi. After injection, the mould was set to cool down for three minutes before opening and removing the sample. The first ten samples of each run were discarded in order to stabilise the process. The rest of the samples were chosen for their characterisation.

Fourier transform infrared spectroscopy (FTIR) was carried out on a Bruker Tensor 37 spectrometer fitted with a diamond ATR device (resolution $1 \mathrm{~cm}^{-1}$ ). A differential scanning calorimeter (DSC), Perkin Elmer DSC-7, was used to determine the crystallinity and the nucleating behaviour of nanocomposites. This was calibrated with an indium standard using a constant nitrogen flow both in the sample and in the reference chambers. All samples weighed approximately $6 \mathrm{mg}$ and were sealed within aluminium pans. The samples were heated up to $280^{\circ} \mathrm{C}$ for five minutes and then they were cooled down at $10^{\circ} \mathrm{C} / \mathrm{min}$. The percentage of crystallinity $\left(\mathrm{X}_{\mathrm{c}}\right)$ was calculated by integrating the melting curves for obtaining the sample heat of fusion and dividing by the heat of fusion of $100 \%$ crystalline nylon 6,6, taken as $197 \mathrm{~J} / \mathrm{g}$ [24]. Wide angle $\mathrm{X}$-ray diffraction (WAXD) measurements were obtained in PANalytical X'Pert Pro X-ray diffraction equipment with $\mathrm{Cu}$ $\mathrm{K} \alpha$ radiation $(k=0.154 \mathrm{~nm})$. The scanning rate was $0.05^{\circ} / \mathrm{s}$. The diffraction patterns were fitted using Gaussian functions in Origin 8.5 in order to obtain a broad amorphous halo and sharp peaks from the reflections of the crystalline peaks, as it has been reported by other research groups [25-27]. This procedure was used to evaluate the crystallinity index (CI) obtained by the following equation:

$$
\mathrm{CI}=\frac{A_{c}}{A_{c}+A_{a}},
$$

where $A_{c}$ is the integrated area underneath the crystalline peaks and $A_{a}$ is the integrated area of the amorphous halo $[25,27]$. The crystallite sizes perpendicular to the diffraction (hkl) planes, $L_{\mathrm{hkl}}$ in nanometres, were obtained by applying Scherrer's equation:

$$
L_{\mathrm{hkl}}=\frac{k \lambda}{\beta \cos \theta},
$$

where $k$ is the Scherrer factor, taken as $0.891[19,28], \lambda$ is the $\mathrm{X}$-ray wavelength, $\beta=\left(B^{2}-b_{0}^{2}\right)^{1 / 2}$ is the pure line breadth, $B$ is a measured half width of the experimental peak, $b_{0}$ is the instrumental broadening factor which is 0.12 for the diffractometer employed, and $\theta$ is the Bragg angle. Thermomechanical properties of the nanocomposites were determined using a dynamic mechanical analyser (DMA), TA Instruments DMA 2980. Samples of $30 \times 10 \times 2 \mathrm{~mm}^{3}$ were analysed in dual cantilever mode from room temperature to $200^{\circ} \mathrm{C}$ at a frequency of $1 \mathrm{~Hz}$ and a heating rate of $5^{\circ} \mathrm{C} / \mathrm{min}$. Thermogravimetric analysis (TGA) was carried out using an SDT Q600
V20.5 Build 15 equipment. $10 \mathrm{mg}$ of the samples was placed into alumina pans and heated up from 25 to $600^{\circ} \mathrm{C}$ under a nitrogen flow of $100 \mathrm{~mL} / \mathrm{min}$. Scanning electron microscopy (SEM) investigation was performed using a JEOL JSM 6060 microscope with an acceleration voltage of $25 \mathrm{kV}$. The samples were cryogenically broken in liquid nitrogen and gold was sputter-coated on the fractured surface.

\section{Results and Discussion}

FTIR spectroscopy has been used for determining the structural units present in pure nylon 6,6 and nanofiller reinforced injection moulded samples. The FTIR spectra are presented in Figure 1(a) showing the samples with the highest content of carbon nanofillers. The peak at $\sim 935 \mathrm{~cm}^{-1}$ is due to the amide axial deformation of $\mathrm{C}-\mathrm{C}=\mathrm{O}$ [29]. The angular deformation of $\mathrm{C}=\mathrm{O}$ occurs at $\sim 1140 \mathrm{~cm}^{-1}$ [30]. The angular deformation out of plane of amide III is located at $\sim 1200 \mathrm{~cm}^{-1}$ [29]. The C$\mathrm{C}$ skeletal vibration is shown at $\sim 1275 \mathrm{~cm}^{-1}$ [29]. The amide III band $/ \mathrm{CH}_{2}$ wagging is located at $\sim 1368 \mathrm{~cm}^{-1}$ [31]. The peaks in the $2800-3000 \mathrm{~cm}^{-1}$ region correspond to the $\mathrm{CH}_{2}$ stretching and to the $\mathrm{N}-\mathrm{H}$ axial deformation [29]. The peak at $\sim 3300 \mathrm{~cm}^{-1}$ is due to the $\mathrm{N}-\mathrm{H}$ stretching vibrations [30]. Our research group has explained the interactions of the functionalised carbon nanomaterials with the nylon 6,6 matrix as seen in FTIR spectra [8]. In this case these interactions are not as noticeable as the ones found in the electrospun nanocomposites recently developed. However, as displayed in Figure 1(b), bands corresponding to methylene stretching and related to conformational changes are red shifted when the nanofillers are incorporated [32]; this change to lower frequencies is clearer in the band located at $2930 \mathrm{~cm}^{-1}$, indicating that the addition of carbon nanomaterials affects the polymer chain order. There is ongoing work to explain the behaviour of the perfection in the short-range ordered structures by this technique; however, their discussion is beyond the scope of this paper.

The melting and crystallisation temperatures of the injection moulded nanocomposites are shown in Tables 1 and 2. All melting thermograms showed a broad peak at $\sim 260^{\circ} \mathrm{C}$ attributed to the melting of $\alpha$-crystals [33]. There was also a very slight broad shoulder on the low temperature side at $\sim 250^{\circ} \mathrm{C}$ indicating crystallite morphological changes [19] or melting of small and less stable crystalline units [24]. There were no significant variations in the melting temperature between nylon 6,6 and the nanofiller reinforced samples. As shown in Table 1, the crystallinity in the nanocomposites in most cases increased marginally as a function of nanofiller content, except in f-CNT based nanocomposites. This can be explained from a kinetic point of view. The nucleation in the polymer is a rate-limiting process and the addition of nanofillers increases the nucleation rate during cooling and hence the fractional crystallinity [33]. The opposite behaviour provided by $\mathrm{f}-\mathrm{CNT}$ has also been found in our previous research of electrospun nanocomposites [7]. As described in this previous publication, oxidised carbon nanofillers were used for obtaining the amino functionalised ones where the amount of carboxylic groups in OCNT was higher 


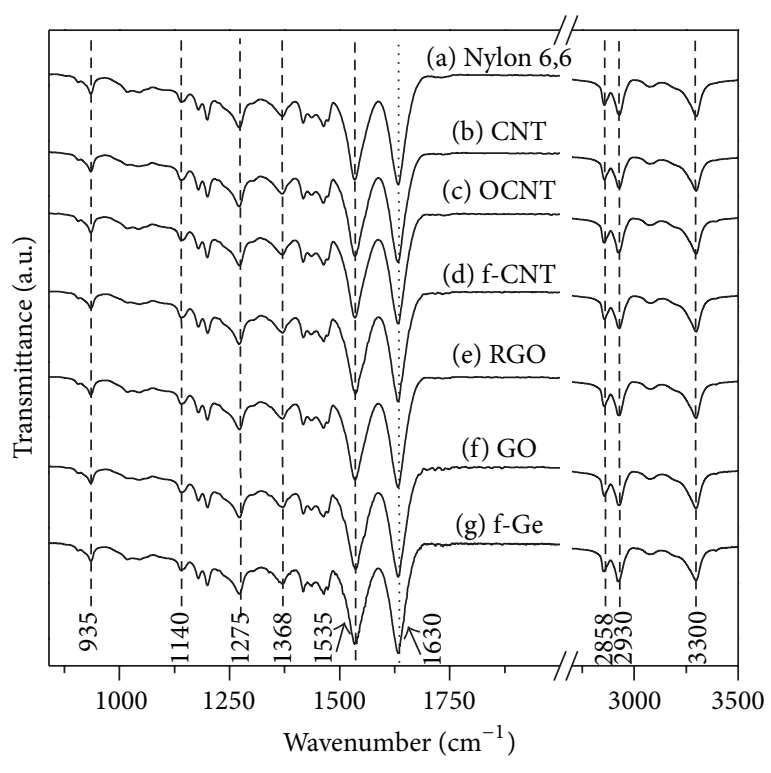

(a)

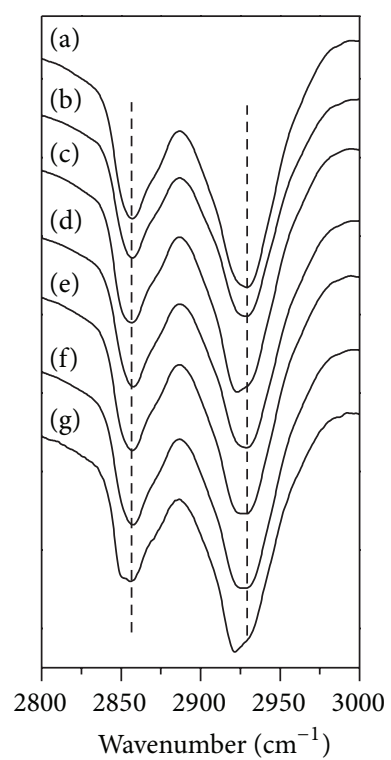

(b)

FIGURE 1: FTIR spectra of (a) nylon 6,6 and nanocomposites containing $0.5 \mathrm{wt} . \%$ nanofillers and (b) zoom in of the $2800-3000 \mathrm{~cm}^{-1}$ region.

TABLE 1: Crystallisation properties obtained from melting curves of DSC.

\begin{tabular}{|c|c|c|c|c|c|c|}
\hline Nylon 6,6 & \multicolumn{3}{|c|}{ Melting temperature, ${ }^{\circ} \mathrm{C}$} & \multicolumn{3}{|c|}{ Percentage of crystallinity, \% } \\
\hline \multirow{2}{*}{ Nanofiller } & \multicolumn{3}{|c|}{ Weight \% } & \multicolumn{3}{|c|}{ Weight \% } \\
\hline & 0.1 & 0.3 & 0.5 & 0.1 & 0.3 & 0.5 \\
\hline CNT & 263.8 & 264.9 & 263.2 & 37.8 & 38.1 & 38.1 \\
\hline OCNT & 263.8 & 263.8 & 263.2 & 38.8 & 39.1 & 39.3 \\
\hline f-CNT & 262.6 & 263.8 & 263.8 & 42.0 & 38.5 & 38.1 \\
\hline RGO & 264.3 & 264.4 & 264.3 & 38.0 & 38.8 & 38.9 \\
\hline GO & 263.2 & 263.2 & 263.2 & 39.1 & 40.9 & 41.0 \\
\hline $\mathrm{f}-\mathrm{Ge}$ & 264.3 & 263.2 & 263.2 & 38.1 & 40.8 & 41.0 \\
\hline
\end{tabular}

TABLE 2: Crystallisation temperatures obtained from crystallisation curves of DSC.

\begin{tabular}{lccccccc}
\hline Nylon 6,6 & \multicolumn{1}{c}{$231.8^{\circ} \mathrm{C}$} \\
\hline \multirow{2}{*}{ Nanofiller } & \multicolumn{3}{c}{ Weight \% } & Nanofiller & \multicolumn{3}{c}{ Weight \% } \\
& 0.1 & 0.3 & 0.5 & & 0.1 & 0.3 & 0.5 \\
\hline CNT & 235.2 & 234.6 & 235.2 & RGO & 234.0 & 234.0 & 234.0 \\
OCNT & 235.2 & 234.6 & 235.7 & GO & 233.5 & 233.5 & 233.5 \\
f-CNT & 234.0 & 234.0 & 234.6 & f-Ge & 233.5 & 233.5 & 232.9 \\
\hline
\end{tabular}

than in GO. Assuming the same amount of $-\mathrm{COOH}$ was converted to $-\mathrm{NH}_{2}$, the increasing content of amino groups with the addition of $\mathrm{f}$-CNT hindered the diffusion and arrangement of long polymer chains resulting in a decrease in crystallinity. This can be also related to poor dispersion of $\mathrm{f}$ $\mathrm{CNT}$ as it will be seen later in the nanocomposite mechanical response. Figure 2 reveals nylon 6,6 crystallisation peaks became broader and decreased in intensity upon addition of nanofillers. This has been attributable to a wider crystal size distribution in the polymer [16]. In addition, the nanocomposites showed a very modest increase in crystallisation temperatures $\left(T_{c}\right)$, as seen in Table 2 . The increase was more evident in CNT based nanocomposites; these samples displayed slightly higher $T_{c}$ than graphene based nanocomposites. Other authors $[17,34]$ have shown more noticeable results regarding the nucleating effect of CNTs and graphene based nanofillers using higher content of nanomaterials. $\mathrm{Xu}$ et al. [20] studied poly(L-lactide) nanocomposites using FTIR and found that the induction process of crystallisation due to graphene is slower than the process due to CNTs because lattice matching plays a dominant role in surface-induced crystallisation. The polymer chains adsorbed on the surface of graphene need more time to adjust their conformations, making the induction process more complex [20]. In contrast, the crystallisation thermograms obtained from the injection moulded nanocomposites show interesting differences between both nanofillers. Graphene based nanocomposites displayed sharper crystallisation curves than CNT based nanocomposites, as shown by the lower values of full width at 


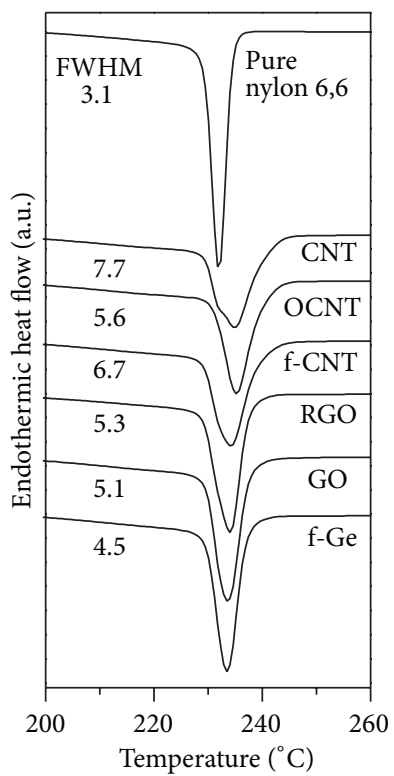

(a)

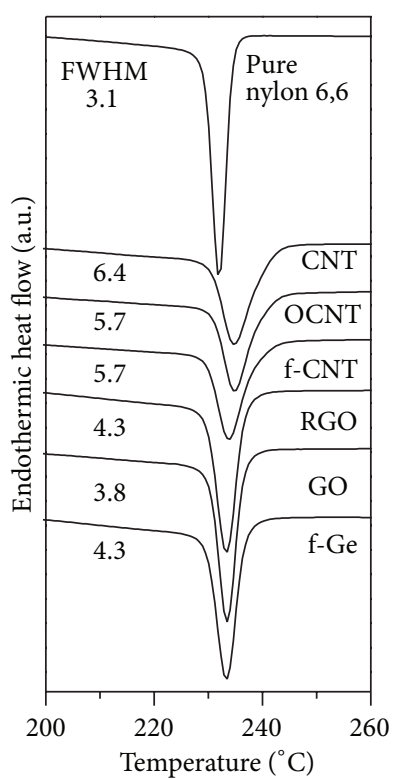

(b)

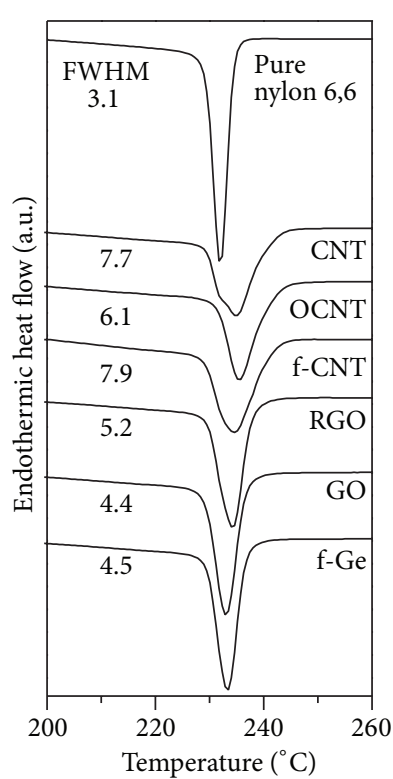

(c)

FIGURE 2: Cooling thermograms of nylon 6,6 and nanocomposites containing (a) 0.1 wt.\%, (b) 0.3 wt.\%, and (c) 0.5 wt.\% nanofillers.

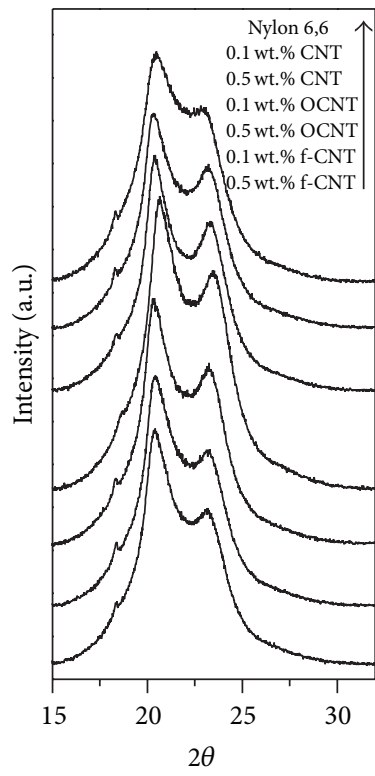

(a)

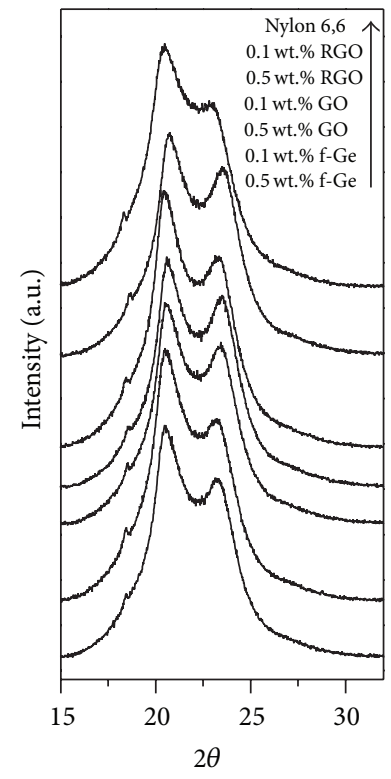

(b)

FIGURE 3: X-ray diffractograms of nylon 6,6, (a) carbon nanotube based nanocomposites and (b) graphene based nanocomposites.

half maximum (FWHM) included in Figure 2. This indicates that while CNTs accelerate the nucleation process, most nylon 6,6 crystals are grown in a shorter time in graphene based nanocomposites. Similar behaviour in crystallisation thermograms and crystallisation rate has been found in polypropylene nucleated with exfoliated graphite [35]. This effect can be attributed to the large surface area of graphene favouring the reduction of interfacial free energy.

The crystallinity of the samples was also characterised by WAXD. The diffraction patterns are displayed in Figure 3.
This polymer has two characteristic diffraction signals located at $\sim 20^{\circ}$ and $\sim 23^{\circ}$. The spacing of them is approximately $0.44 \mathrm{~nm}$ and $0.37 \mathrm{~nm}$, respectively. The former is a project value of the interchain distance within the hydrogenbonded sheet and the latter represents the intersheet distance [18]. These peaks correspond to the (100) and (010/110) crystalline planes of $\alpha$-crystals which have a triclinic unit cell $[19,24]$. The values of CI are included in Table 3; these values agree with the $X_{c}$ calculated from DSC analyses. Furthermore, Figure 3 shows that the polymer crystalline peaks are 
TABLE 3: Crystallisation properties obtained from WAXD.

\begin{tabular}{|c|c|c|c|c|c|c|c|c|c|}
\hline \multirow{2}{*}{ Nylon 6,6 } & \multicolumn{3}{|c|}{$L_{(100)}, \mathrm{nm}$} & \multicolumn{3}{|c|}{$L_{(010 / 110)}, \mathrm{nm}$} & \multicolumn{3}{|c|}{$\mathrm{CI}$} \\
\hline & \multicolumn{3}{|c|}{4.46} & \multicolumn{3}{|c|}{4.01} & \multicolumn{3}{|c|}{0.37} \\
\hline \multirow{2}{*}{ Nanofiller } & \multicolumn{3}{|c|}{ Weight, \% } & \multicolumn{3}{|c|}{ Weight, \% } & \multicolumn{3}{|c|}{ Weight, \% } \\
\hline & 0.1 & 0.3 & 0.5 & 0.1 & 0.3 & 0.5 & 0.1 & 0.3 & 0.5 \\
\hline CNT & 5.08 & 5.28 & 5.37 & 4.10 & 3.75 & 4.15 & 0.38 & 0.39 & 0.39 \\
\hline OCNT & 4.99 & 4.91 & 5.10 & 4.16 & 4.18 & 4.01 & 0.38 & 0.39 & 0.40 \\
\hline f-CNT & 5.07 & 5.06 & 4.87 & 3.83 & 3.97 & 3.94 & 0.41 & 0.41 & 0.40 \\
\hline RGO & 4.86 & 4.92 & 5.03 & 4.34 & 4.30 & 4.05 & 0.38 & 0.39 & 0.39 \\
\hline GO & 4.88 & 4.75 & 4.82 & 4.25 & 4.21 & 4.22 & 0.39 & 0.40 & 0.40 \\
\hline f-Ge & 4.78 & 4.91 & 4.56 & 4.01 & 4.20 & 4.24 & 0.39 & 0.40 & 0.40 \\
\hline
\end{tabular}

TABLE 4: Thermal properties of nylon 6,6 and the nanocomposites.

\begin{tabular}{|c|c|c|c|c|c|c|c|}
\hline \multirow{4}{*}{$\begin{array}{c}\text { Nylon 6,6 } \\
\text { Nanofiller }\end{array}$} & \multirow{2}{*}{\multicolumn{3}{|c|}{$\begin{array}{c}\text { Glass transition temperature, }{ }^{\circ} \mathrm{C} \\
71.8\end{array}$}} & \multirow{2}{*}{\multicolumn{2}{|c|}{$\begin{array}{l}\text { Temperature at which } 10 \text { weight } \\
\% \text { loss occurs, }{ }^{\circ} \mathrm{C} \\
387.4\end{array}$}} & \multirow{2}{*}{\multicolumn{2}{|c|}{$\begin{array}{l}\text { Temperature at which } 50 \text { weight } \\
\% \text { loss occurs, }{ }^{\circ} \mathrm{C} \\
421.2\end{array}$}} \\
\hline & & & & & & & \\
\hline & \multicolumn{3}{|c|}{ Weight, $\%$} & \multicolumn{2}{|c|}{ Weight, $\%$} & \multicolumn{2}{|c|}{ Weight, $\%$} \\
\hline & 0.1 & 0.3 & 0.5 & 0.1 & 0.5 & 0.1 & 0.5 \\
\hline $\mathrm{CNT}$ & 78.3 & 78.0 & 76.4 & 387.5 & 386.6 & 418.8 & 418.7 \\
\hline OCNT & 77.7 & 79.3 & 80.0 & 389.5 & 389.2 & 421.1 & 421.6 \\
\hline f-CNT & 81.4 & 78.7 & 77.7 & 388.1 & 387.6 & 421.1 & 421.3 \\
\hline RGO & 76.9 & 80.9 & 79.9 & 391.4 & 390.9 & 422.5 & 421.5 \\
\hline $\mathrm{GO}$ & 78.1 & 72.8 & 78.9 & 388.7 & 392.8 & 418.6 & 426.0 \\
\hline $\mathrm{f}-\mathrm{Ge}$ & 78.3 & 77.7 & 79.6 & 390.6 & 389.6 & 421.7 & 422.0 \\
\hline
\end{tabular}

sharper after addition of nanofillers, indicating an increase in crystallite size meaning enhanced crystal perfection. Table 3 also shows the increased crystallite size values when compared to pure polymer. Typically, the addition of nucleating agents is expected to produce smaller and less perfect crystals. However other composite studies have shown similar results as in this case [16, 34, 36]. Sandler et al. [34] explained that the early nucleation leaves more space for the heteronucleated crystals to grow before homonucleation within the rest of the matrix leads to impingement. The crystal sizes indicate that the preferential growth of nylon 6,6 crystalline structures is in the perpendicular direction of (100) plane in all samples.

Figure 4 shows the plots of storage modulus versus temperatures of nylon 6,6 and the nanocomposites, showing the percentage increases in this property compared to pure polymer (values taken at $30^{\circ} \mathrm{C}$ ). These results demonstrate the polymer enhanced stiffness imposed by the carbon nanofillers and also these storage modulus values match the crystallinity trend upon nanofiller addition. The predominant effect in this property can be attributed to the addition of the rigid carbon nanofillers [21]. Besides, the functionalisation effect in the mechanical response is evident in CNT based nanocomposites; polymer reinforced with pristine CNTs showed that the modulus increased up to $17 \%$ at the highest content. After oxidation CNTs at the same loading provide a better dispersion in the matrix resulting in an increase of $27 \%$ compared to pure nylon 6,6. Amino functionalised CNTs could have been agglomerated at high content and consequently the modulus was enhanced only by a $17 \%$ at a 0.5 wt.\% loading; however the incorporation of 0.1 wt. $\%$ of this nanofiller provided a $30 \%$ enhancement in the storage modulus. Graphene based nanocomposites showed the best mechanical response. Both RGO and $\mathrm{f}-\mathrm{Ge}$ increased the modulus up to $\sim 30 \%$ at the highest content. The very similar results in these nanocomposites can be related to the reduction method employed in this work. The infrared analysis shown in our previous publication gave a hint of a few amine groups adsorbed on the graphene surface due to the reducing agent used [8]; this provided a better dispersion of the nanofiller and favoured the mechanical properties. The incorporation of $0.5 \mathrm{wt} . \% \mathrm{GO}$ resulted in an increase up to $44 \%$ in nylon 6,6 storage modulus. Previous studies have shown that graphene provides better mechanical performance when compared to CNTs [21, 22]. The large 2D structure of graphene allows the polymer to have a larger interfacial area which favours stress transfer between both materials. Nylon nanocomposites obtained from solution mixing and melt compounding techniques have shown similar modulus results when using higher content of CNTs or graphene [37-40].

The glass transition temperatures $\left(T_{g}\right)$ can be evaluated using the $\tan \delta$ plot obtained from DMA, which is related to the reduction of vibration of material, that is, damping [41]. Table 4 shows the values of this property which were obtained from the maximum of the $\tan \delta$ plots displayed in Figure 5. There was no consistent effect produced by the carbon structures, functionalisation, or content in the glass transition 


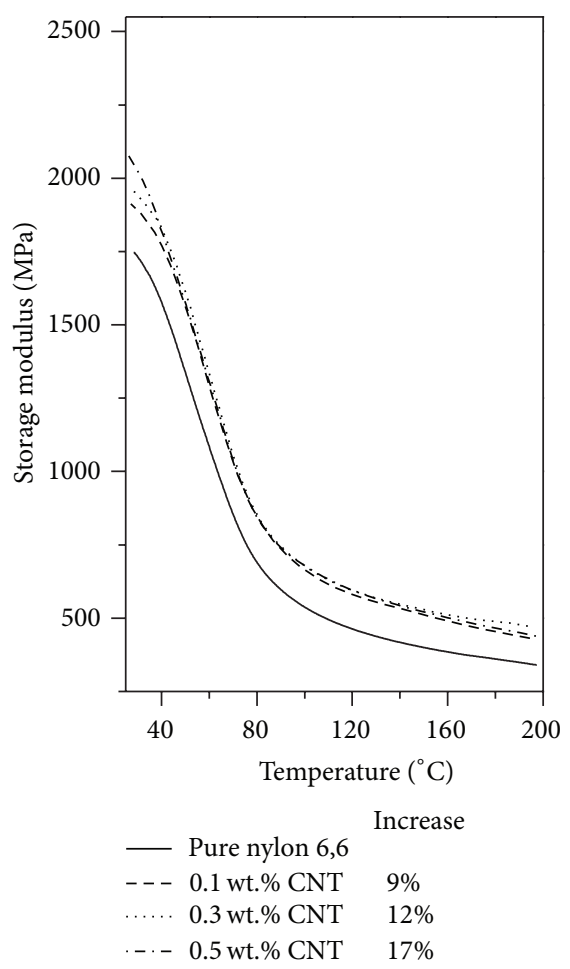

(a)

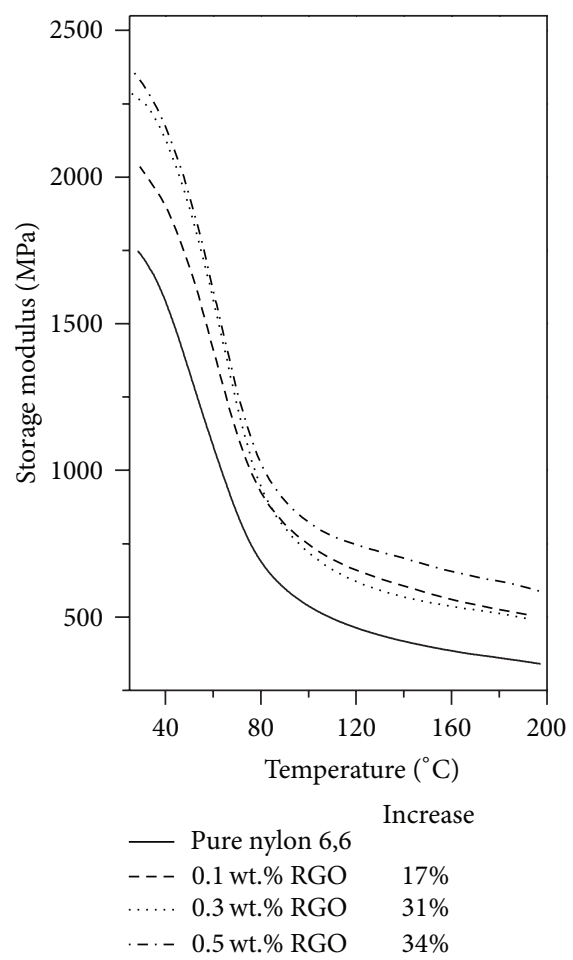

(d)
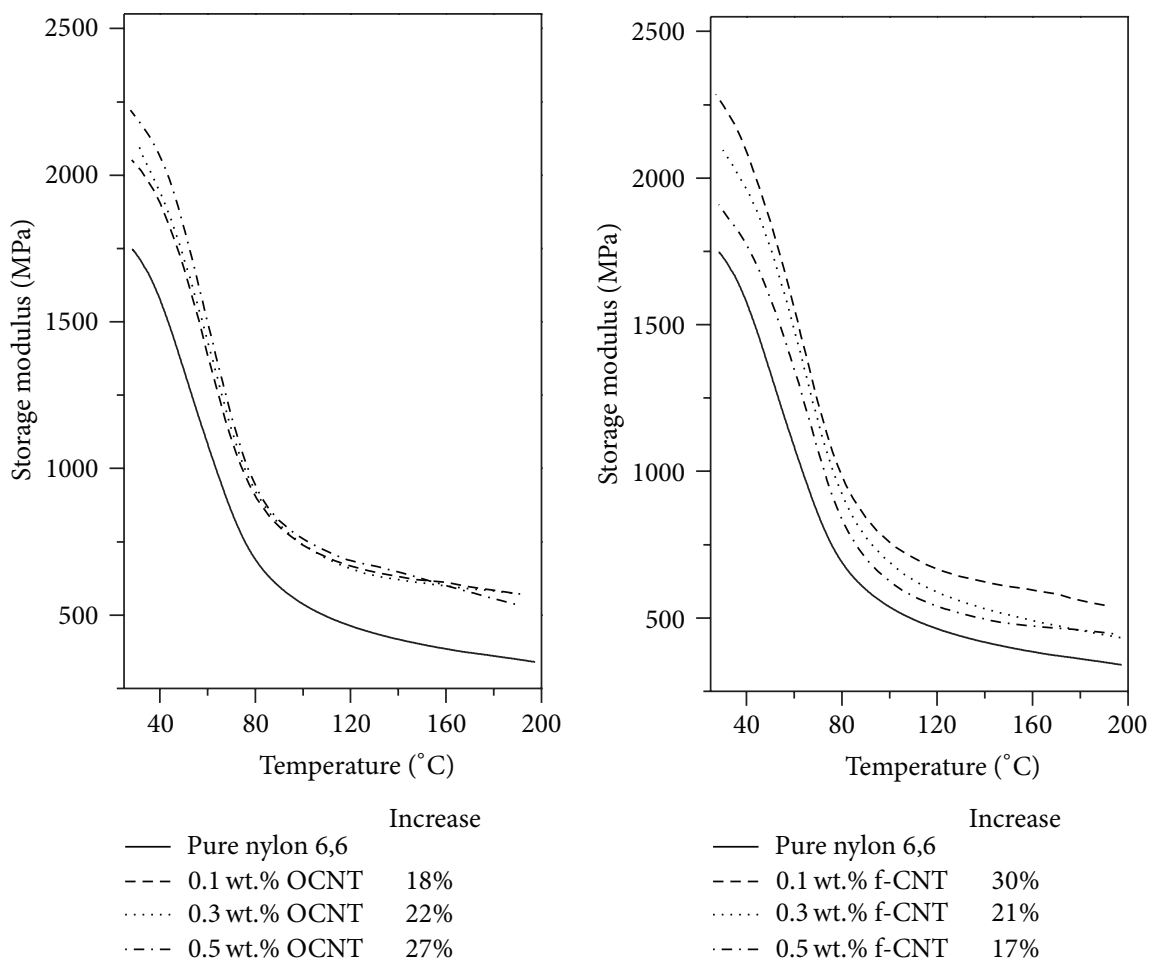

(b)

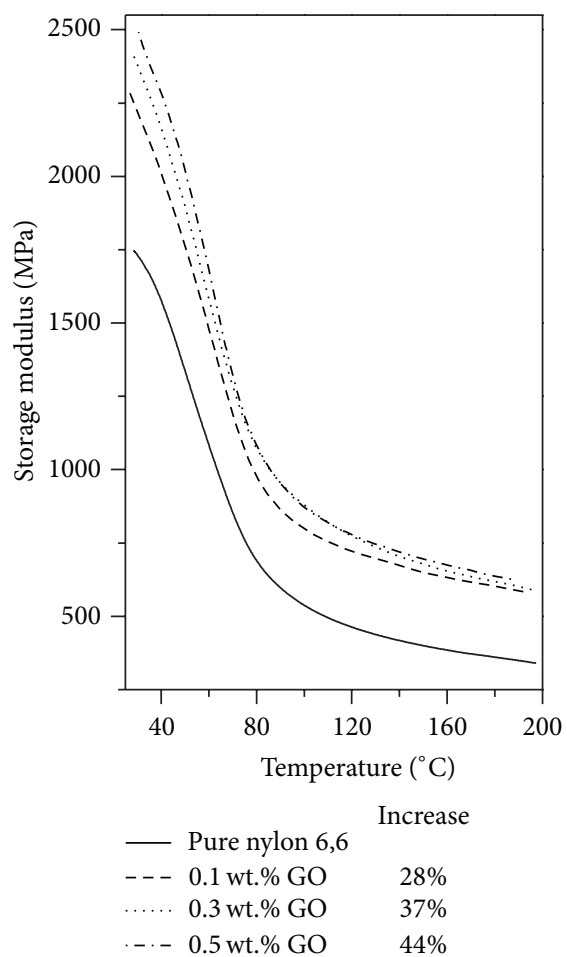

(e)

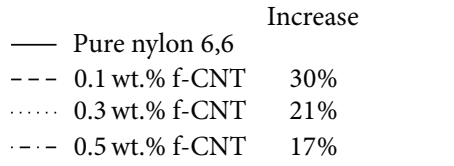

(c)

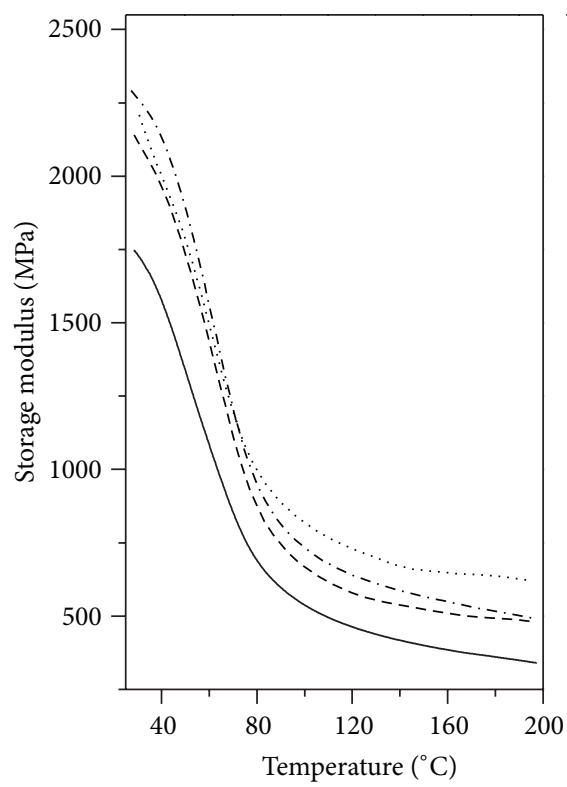

(f)

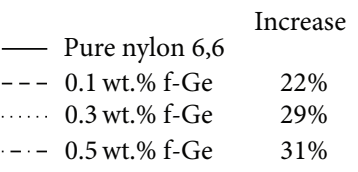

Figure 4: Storage modulus of nylon 6,6 and (a), (b), and (c) carbon nanotube based nanocomposites and (d), (e), and (f) graphene based nanocomposites. 

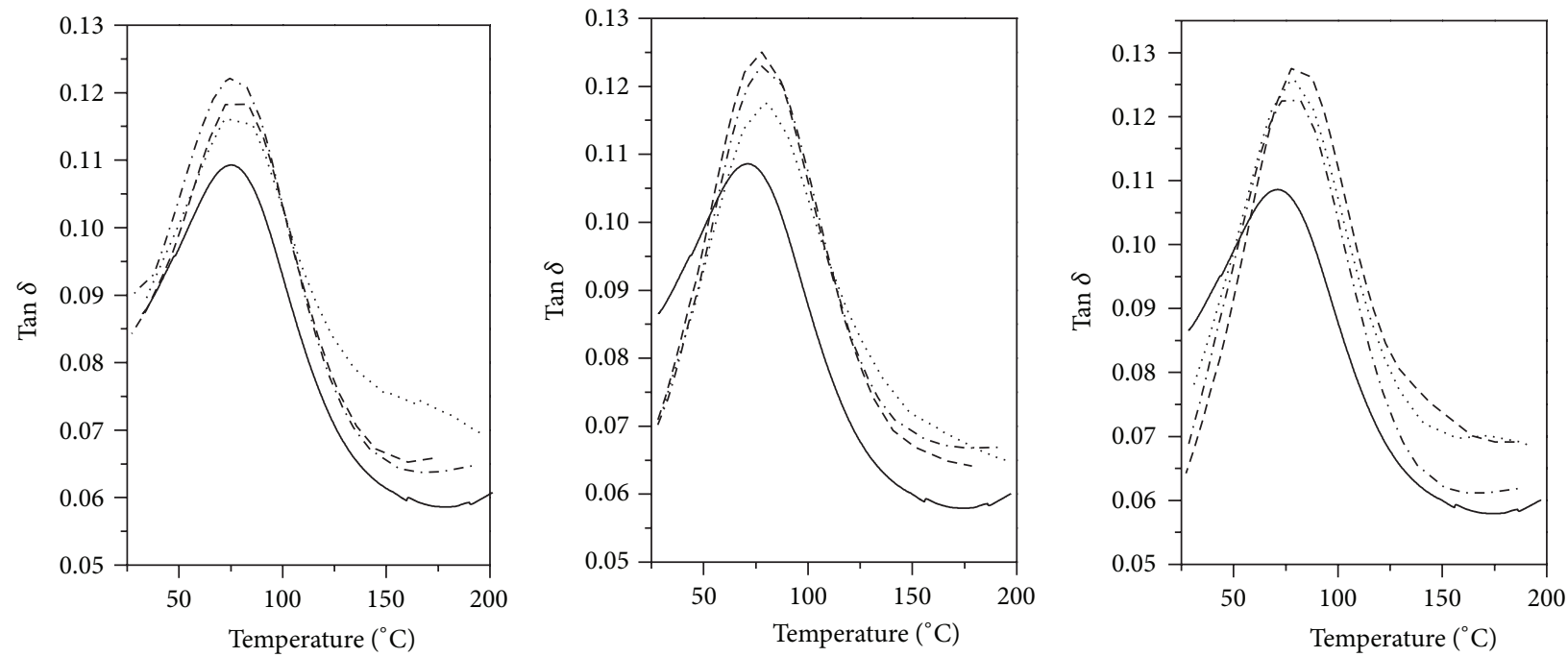

Nanofiller content

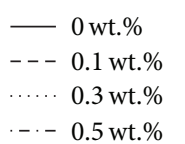

Nanofiller content

- 0 wt.\%

- - 0.1 wt.\%

…. 0.3 wt. $\%$

- - 0.5 wt. $\%$

(b)

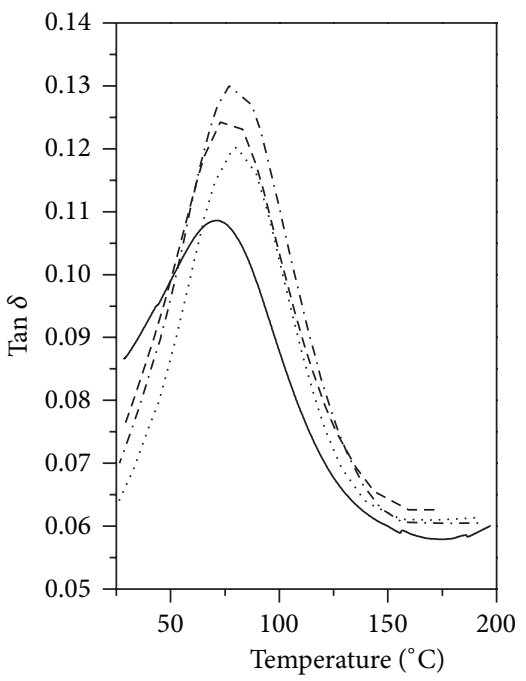

Nanofiller content

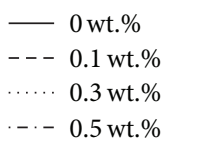

(d)

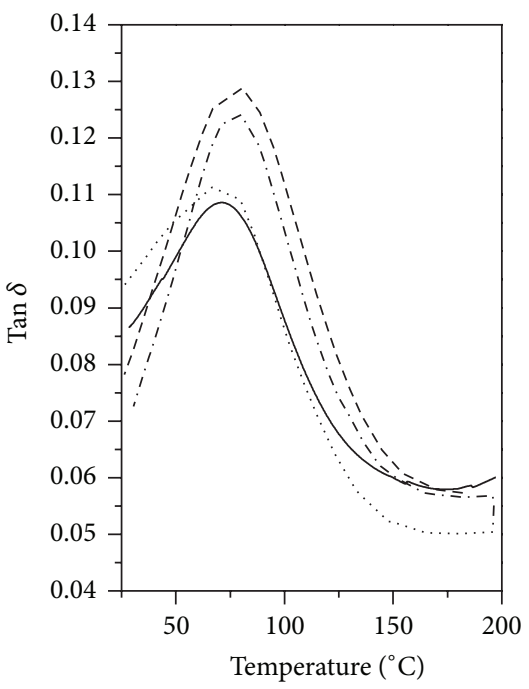

Nanofiller content

$$
\begin{aligned}
& \text { - } 0 \text { wt. } \% \\
& ---0.1 \text { wt. } \% \\
& \text { … } 0.3 \text { wt. } \%
\end{aligned}
$$$$
\text { - - }-0.5 \text { wt } \%
$$

(e)
Nanofiller content

- 0 wt.\%

- - - 0.1 wt.\%

…. 0.3 wt. $\%$

... 0.5 wt. $\%$

(c)

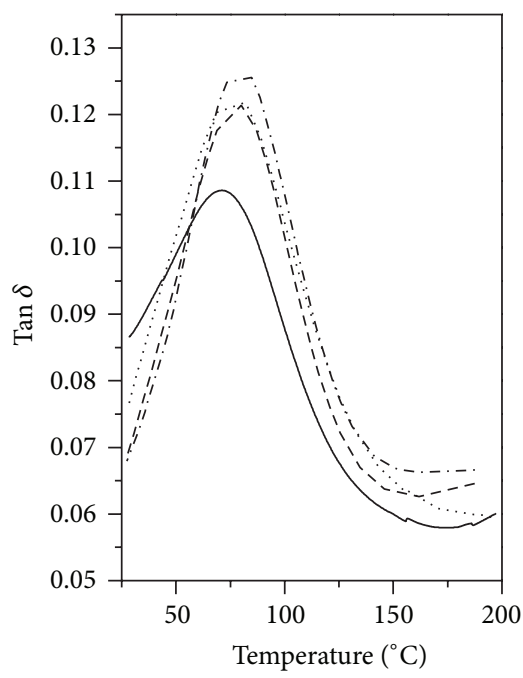

Nanofiller content

- 0 wt.\%

- - 0.1 wt.\%

… 0.3 wt. $\%$

-. - 0.5 wt. $\%$

(f)

Figure 5: Tan $\delta$ of nylon 6,6 and (a) CNT, (b) OCNT, and (c) f-CNT nanocomposites and (d) RGO, (e) GO, and (f) f-Ge nanocomposites.

of polymer, as has also been observed in other works [12, $42]$. However there is a moderate increase in this property caused by the restriction in molecular mobility of the matrix imposed by the nanofillers and also the enhanced stiffness of graphene composites caused a damping variation and hence the nanocomposite $T_{g}$ was increased [12, 41]. This property was enhanced up to $\sim 9^{\circ} \mathrm{C}$ when incorporating $0.1 \mathrm{wt} . \% \mathrm{f}$ CNT or 0.3 wt. $\%$ RGO. The temperature of decomposition
$\left(T_{d}\right)$ of the lowest and highest filler content in the nylon 6,6 was investigated; Table 4 also summarises the results obtained from TGA measurements. The temperatures at which $10 \%$ and $50 \%$ weight loss occurred were the criteria for determining the thermal stability. In most cases, the nanocomposite $T_{d}$ remained unchanged. Enhanced thermal stability has been associated to the filler good dispersion in the polymer; the nanofillers act as restriction sites reducing segmental 


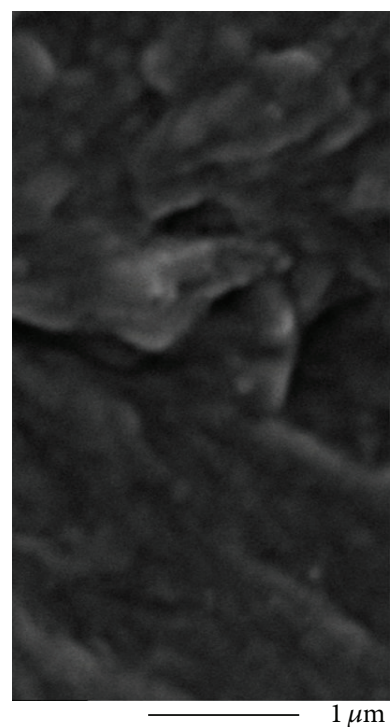

(a)

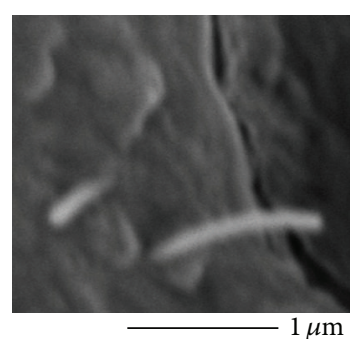

(b)

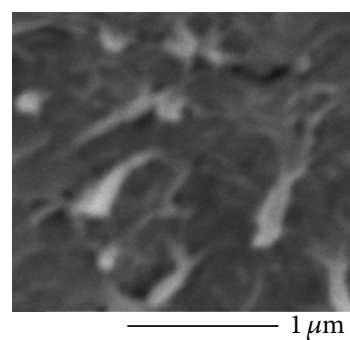

(e)

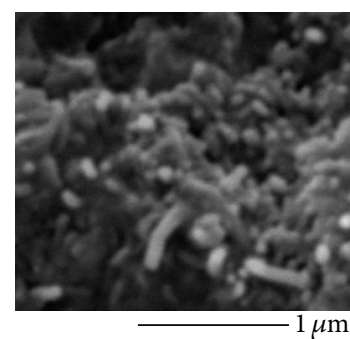

(c)

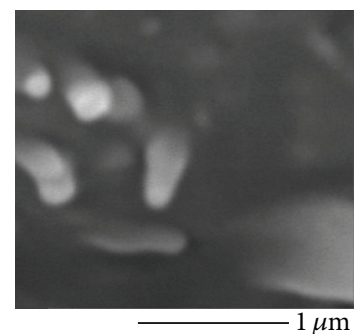

(f)

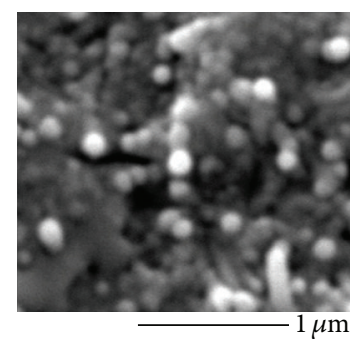

(d)

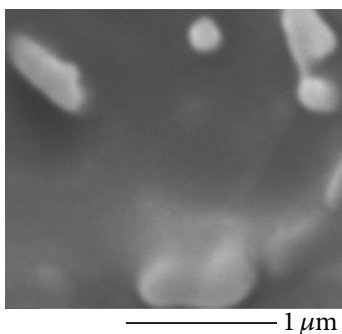

(g)

FIGURE 6: SEM micrograph of fracture surface of (a) neat nylon 6,6 and higher magnification micrographs of fracture surface of nanocomposites containing 0.5 wt. \% of (b) CNT, (c) OCNT, (d) f-CNT, (e) RGO, (f) GO, and (g) f-Ge.

mobility of the polymer chains. The reduced mobility in turn assists in preventing scission of chains driven by thermal excitation [43]. Liu et al. [44] obtained well-dispersed nanocomposites of PMMA/CNTs and TGA analyses showed that $T_{d}$ is similar to that of the polymer when a nitrogen atmosphere was used. Other studies $[12,40,43]$ have indicated that the $T_{d}$ of nanocomposites is comparable to the matrix when tested under an inert atmosphere. Li et al. [40] concluded that the presence of CNTs hinders the thermooxidation of nylon 6 under air and thus increases the thermal stability of the polymer. However, this effect was not found for all the CNTs/nylon 6 composites under nitrogen atmosphere without the participation of oxygen [40]. Despite the results obtained, the GO addition into nylon 6,6 enhanced this property. The GO nanocomposites displayed an increase of $\sim 6^{\circ} \mathrm{C}$ and $\sim 5^{\circ} \mathrm{C}$ at $10 \mathrm{wt} . \%$ and $50 \mathrm{wt} . \%$ loss, respectively, for the highest nanofiller content.

Figures 6, 7, and 8 show the cryogenic fracture surface of pure polymer and nanocomposites. High magnification micrographs are included in Figure 6 showing the embedding of the carbon nanomaterials in the polymer matrix and protruding of some of them. Figures 6(b), 6(c), and 6(d) show a few CNTs pulled-out of nylon 6,6 matrix. On the other hand, Figures 6(e), 6(f), and 6(g) exhibit the presence of graphene sheets with the edges emerging out of the matrix. The presence of graphene sheets was corroborated by the size of these platelets; GO prepared via chemical routes and sonication typically yield GO sheets with diameters of hundreds of nanometers and rarely exceed a few microns [45]. Therefore, this observation is supported by taking into account that all the graphene based materials employed in this work were obtained from GO (either by reduction or further functionalisation), by doing a close examination of TEM images obtained in previous works $[7,8]$ and also by comparing SEM images of nanocomposites reported by other research groups [46, 47]. Furthermore, the micrographs of neat polymer (Figure 6(a)) and nanocomposites (Figures 7 and 8) show the sample morphology and dispersion of the nanofillers in the reinforced samples. The surface of the nanocomposites appeared coarser than that of the neat polymer by showing many fracture ditches indicating that the nanofillers prevented the crack propagation, as it has been found by other studies of carbon based nanocomposites $[37,44]$. The 1D carbon reinforcements were well dispersed within the matrix as shown by the bright dots attributed to the broken ends of the nanotubes. A few pulled-out nanotubes are shown in the pristine CNT based nanocomposites as indicated by the red arrows in Figures 7(a) and 7(b). The functionalisation of the nanofillers diminished the presence of pulledout nanotubes indicating the good interfacial interaction with the matrix, as seen in Figures 7 (c) to 7(f). Nevertheless, the sample containing $0.5 \mathrm{wt} . \% \mathrm{f}-\mathrm{CNT}$ showed the thickest bright dots, indicating the presence of nanotube agglomerates in this nanocomposite, as it was shown by the response in the mechanical analysis. Figure 8 shows the graphene sheets protruding out of the fracture surface and some of them are indicated by red arrows. The rest of the bright dots appearing in these micrographs can be attributed to the edges of the graphene sheets or small nanosheets. These features show that the graphene sheets were well dispersed and embedded in the nylon matrix. The surface of the nanocomposite containing 0.5 wt. $\%$ f-Ge showed the smoothest surface; however, the graphene sheets were coated with polymer, indicating strong polymer interaction. 


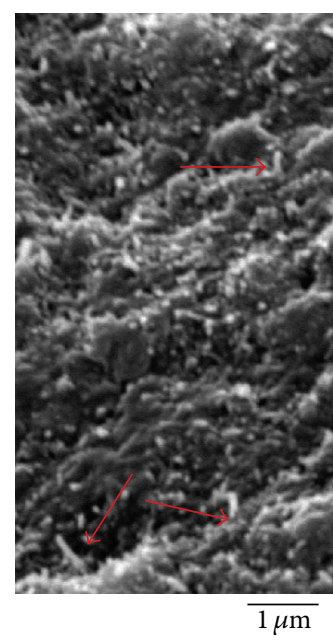

(a)

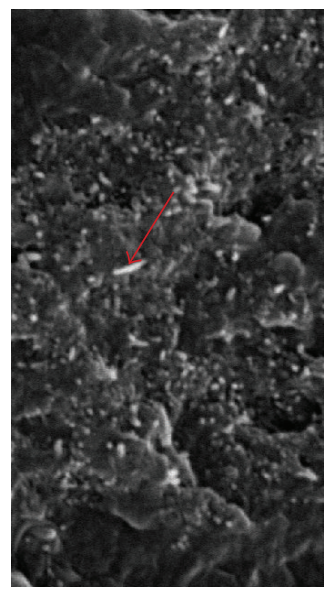

$\overline{1 \mu \mathrm{m}}$

(d)

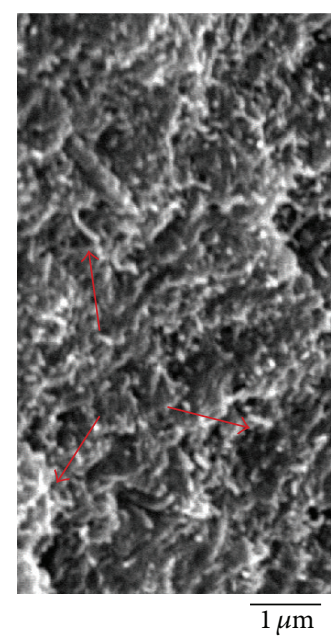

(b)

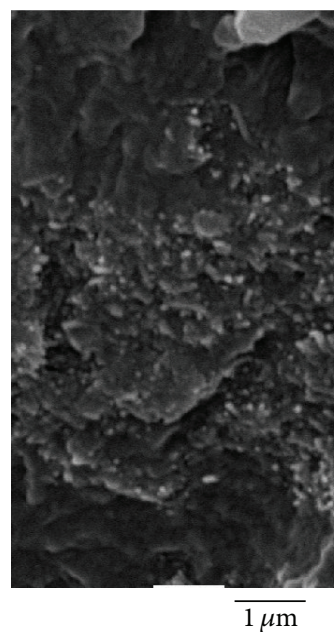

(e)

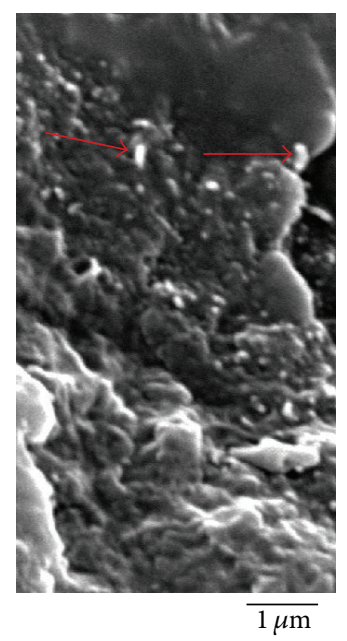

(c)

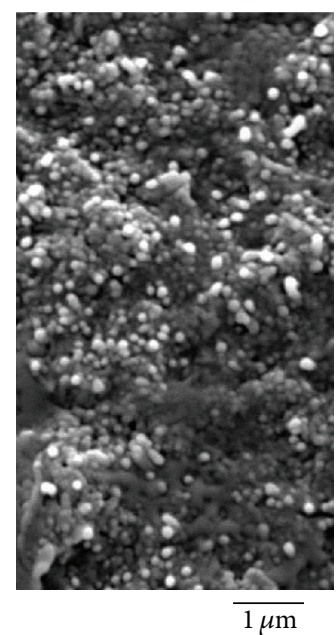

(f)

Figure 7: SEM micrographs of (a) 0.1 wt.\% CNT, (b) 0.5 wt.\% CNT, (c) 0.1 wt.\% OCNT, (d) 0.5 wt.\% OCNT, (e) 0.1 wt.\% f-CNT, and (f) $0.5 \mathrm{wt}$ \% f-CNT nanocomposites.

\section{Conclusions}

Nylon 6,6 was reinforced using 1D and 2D carbon nanofillers. The addition of the nanofillers provided a very little increase in the crystallinity of the polymer and there was no significant influence in this property attributed to the functionalisation of the nanofillers. The crystallisation curves revealed the effect in crystal growth when using differently structured carbon nanofillers. CNT based nanocomposites were crystallised at higher temperatures than graphene based nanocomposites. However the crystal growth in graphene based nanocomposites was faster. The method employed for obtaining the nanocomposites is compatible with current industrial processes and revealed interesting crystal features. All nanofillers favoured the perfection of the crystals. The stiffness of the polymer was increased and the improvement was more noticeable in graphene based nanocomposites. The mechanical response of most nanocomposites was enhanced as the nanofiller content increased. $\mathrm{f}$-CNT nanocomposites showed an opposite behaviour due to the agglomeration of the nanotubes at high content as confirmed by SEM images; however, the modulus was 30\% higher than nylon 6,6 when using 0.1 wt.\% of this nanofiller. GO showed to be the best reinforcing material at all contents when compared with the rest of the nanofillers. In addition, the nanocomposite containing 0.5 wt. $\%$ GO improved the thermal stability by $\sim 5^{\circ} \mathrm{C}$. Graphene based composites showed the best thermomechanical properties owned to the dimensionality of this material. Examination of the neat polymer and nanocomposite fracture surfaces revealed differences between the two types of carbon nanofillers as well as interesting features for the different functionalised reinforcements.

\section{Conflict of Interests}

The authors declare that there is no conflict of interests regarding the publication of this paper. 


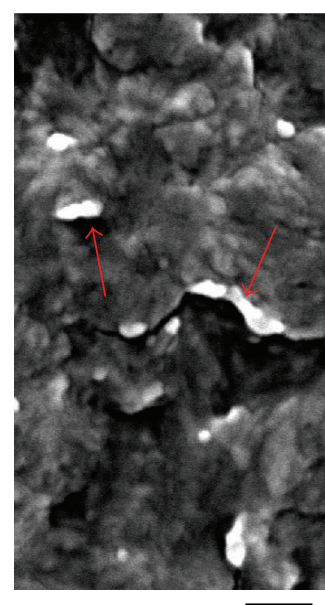

$\overline{1 \mu \mathrm{m}}$

(a)

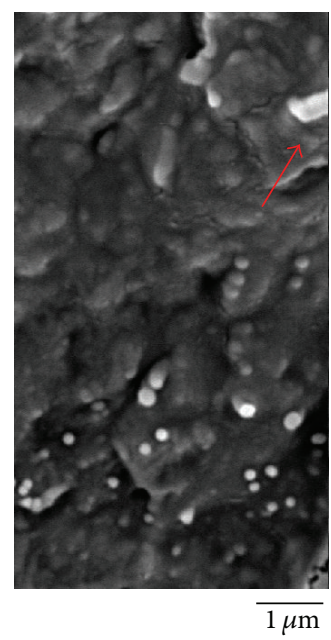

(d)

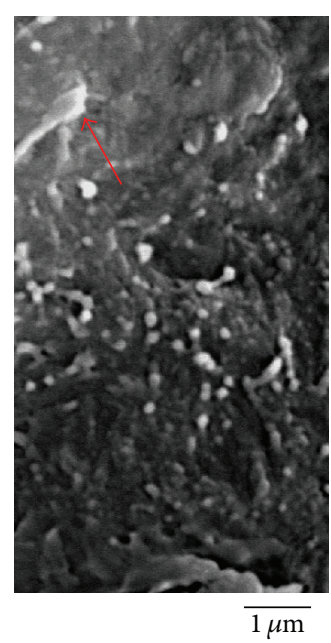

(b)

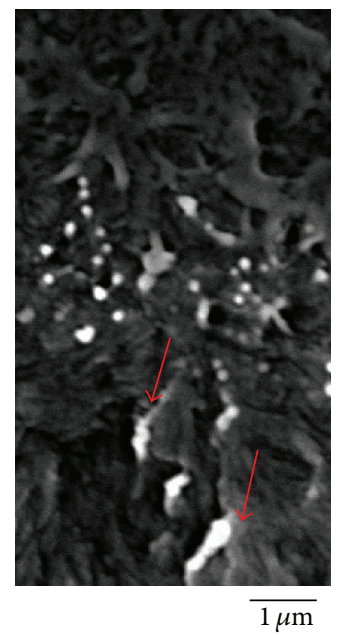

(e)

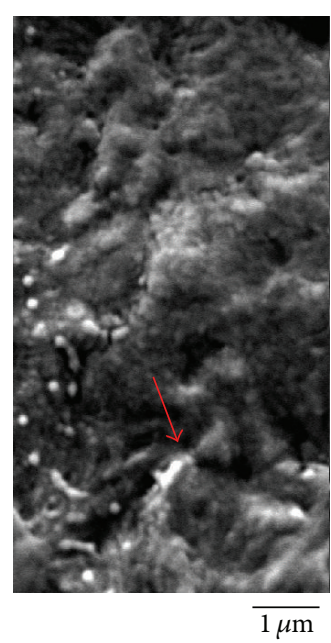

(c)

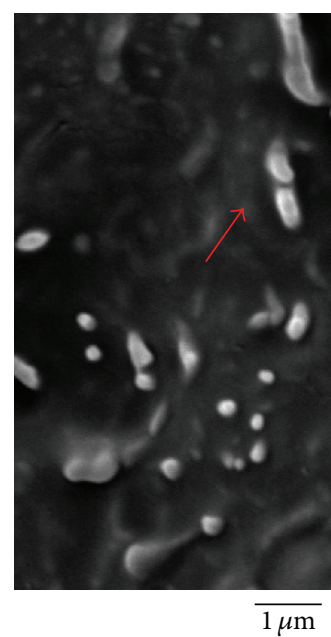

(f)

Figure 8: SEM micrographs of (a) 0.1 wt.\% RGO, (b) 0.5 wt.\% RGO, (c) 0.1 wt.\% GO, (d) 0.5 wt.\% GO, (e) 0.1 wt.\% f-Ge, and (f) 0.5 wt.\% f-Ge nanocomposites.

\section{Acknowledgments}

The authors are grateful to O. Davalos Montoya for her help in DSC analyses, A. L. Rodríguez Villanueva for her assistance in WAXD measurements, and F. Ureña-Nuñez for his help in TGA measurements. They are also grateful to A. del Real López for her assistance in SEM and R. Preza for his technical assistance. Ph.D. student F. Navarro-Pardo is thankful to CONACYT for the Grant no. 213733 and to Universidad Autonóma de Estado de México for the use of facilities. Authors are grateful to PROMEP due to its financial support in this research.

\section{References}

[1] S. Park, J. An, R. D. Piner et al., "Aqueous suspension and characterization of chemically modified graphene sheets," Chemistry of Materials, vol. 20, no. 21, pp. 6592-6594, 2008.
[2] X. Shen, L. Jiang, Z. Ji, J. Wu, H. Zhou, and G. Zhu, "Stable aqueous dispersions of graphene prepared with hexamethylenetetramine as a reductant," Journal of Colloid and Interface Science, vol. 354, no. 2, pp. 493-497, 2011.

[3] V. Datsyuk, M. Kalyva, K. Papagelis et al., "Chemical oxidation of multiwalled carbon nanotubes," Carbon, vol. 46, no. 6, pp. 833-840, 2008.

[4] H. L. Guo, X. F. Wang, Q. Y. Qian, F. B. Wang, and X. H. Xia, "A green approach to the synthesis of graphene nanosheets," ACS Nano, vol. 3, no. 9, pp. 2653-2659, 2009.

[5] W. Chen, L. Yan, and P. R. Bangal, "Preparation of graphene by the rapid and mild thermal reduction of graphene oxide induced by microwaves," Carbon, vol. 48, no. 4, pp. 1146-1152, 2010.

[6] A. L. Martínez -Hernández, C. Velasco-Santos, and V. M. Castaño, "Carbon nanotubes composites: processing, grafting and mechanical and thermal properties," Current Nanoscience, vol. 6, no. 1, pp. 12-39, 2010. 
[7] F. Navarro-Pardo, G. Martínez -Barrera, A. L. Martínez Hernández et al., "Nylon 6,6 electrospun fibres reinforced by amino functionalised 1D and 2D carbon," IOP Conference Series: Materials Science and Engineering, vol. 40, Article ID 012023, 2012.

[8] F. Navarro-Pardo, G. Martínez -Barrera, A. L. Martínez Hernández et al., "Effects on the thermo-mechanical and crystallinity properties of nylon 6, 6 electrospun fibres reinforced with one dimensional (1D) and two dimensional (2D) carbon," Materials, vol. 6, pp. 3494-3513, 2013.

[9] C. Rong, G. Ma, S. Zhang et al., "Effect of carbon nanotubes on the mechanical properties and crystallization behavior of poly(ether ether ketone)," Composites Science and Technology, vol. 70, no. 2, pp. 380-386, 2010.

[10] X. Chen, X. Chen, M. Lin, W. Zhong, X. Chen, and Z. Chen, "Functionalized multi-walled carbon nanotubes prepared by in situ polycondensation of polyurethane," Macromolecular Chemistry and Physics, vol. 208, no. 9, pp. 964-972, 2007.

[11] G. Mago, C. Velasco-Santos, A. L. Martinez-Hernandez, D. M. Kalyon, and F. T. Tisher, "Effect of functionalization on the crystallization behavior of MWNT-PBT nanocomposites," Materials Research Society Symposium Proceedings, vol. 1056, pp. 295-300, 2008.

[12] P. Song, Z. Cao, Y. Cai, L. Zhao, Z. Fang, and S. Fu, "Fabrication of exfoliated graphene-based polypropylene nanocomposites with enhanced mechanical and thermal properties," Polymer, vol. 52, pp. 4001-4010, 2011.

[13] J. Shen, B. Yan, M. Shi et al., "Synthesis of graphene oxide-based biocomposites through diimide-activated amidation," Journal of Colloid and Interface Science, vol. 356, pp. 543-549, 2011.

[14] J. Shen, M. Shi, B. Yan et al., "Covalent attaching protein to graphene oxide via diimide-activated amidation," Colloids and Surfaces B: Biointerfaces, vol. 81, no. 2, pp. 434-438, 2010.

[15] M. Seredych, J. A. Rossin, and T. J. Bandosz, "Changes in graphite oxide texture and chemistry upon oxidation and reduction and their effect on adsorption of ammonia," Carbon, vol. 49, no. 13, pp. 4392-4402, 2011.

[16] A. R. Bhattacharyya, P. Pötschke, L. Häußler, and D. Fischer, "Reactive compatibilization of melt mixed PA6/SWNT composites: mechanical properties and morphology," Macromolecular Chemistry and Physics, vol. 206, no. 20, pp. 2084-2095, 2005.

[17] Y. S. Yun, Y. H. Bae, D. H. Kim, J. Y. Lee, I. J. Chin, and H. J. Jin, "Reinforcing effects of adding alkylated graphene oxide to polypropylene," Carbon, vol. 49, no. 11, pp. 3553-3559, 2011.

[18] Y. Lu, Y. Zhang, G. Zhang, M. Yang, S. Yan, and D. Shen, "Influence of thermal processing on the perfection of crystals in polyamide 66 and polyamide 66/clay nanocomposites," Polymer, vol. 45, no. 26, pp. 8999-9009, 2004.

[19] L. Li, C. Y. Li, C. Ni, L. Rong, and B. Hsiao, "Structure and crystallization behavior of nylon 66/multi-walled carbon nanotube nanocomposites at low carbon nanotube contents," Polymer, vol. 48, no. 12, pp. 3452-3460, 2007.

[20] J. Z. Xu, T. Chen, C. L. Yang et al., "Isothermal crystallization of poly(l-lactide) induced by graphene nanosheets and carbon nanotubes: a comparative study," Macromolecules, vol. 43, no. 11, pp. 5000-5008, 2010.

[21] F. R. Lamastra, D. Puglia, M. Monti et al., "Poly( $\varepsilon$-caprolactone ) reinforced with fibres of poly(methyl methacrylate) loaded with multiwall carbon nanotubes or graphene nanoplateletas," Chemical Engineering Journal, vol. 196, pp. 140-148, 2012.

[22] S. Chatterjee, F. A. Nüesch, and B. T. Chu, "Crystalline and tensile properties of carbon nanotube and graphene reinforced polyamide 12 fibers," Chemical Physics Letters, vol. 557, pp. 9296, 2013.

[23] S. Chatterjee, F. A. Nuesch, and B. T. T. Chu, "Comparing carbon nanotubes and graphene nanoplatelets as reinforcements in polyamide 12 composites," Nanotechnology, vol. 22, no. 27, Article ID 275714, 2011.

[24] D. J. Lin, C. L. Chang, C. K. Lee, and L. P. Cheng, "Fine structure and crystallinity of porous nylon 66 membranes prepared by phase inversion in the water/formic acid/nylon 66 system," European Polymer Journal, vol. 42, no. 2, pp. 356-367, 2006.

[25] N. S. Murthy, "Recent developments in polymer characterization using X-ray diffraction," The Rigaku Journal, vol. 20, no. 1, pp. 15-24, 2004.

[26] A. Marcellan, A. R. Bunsell, L. Laiarinandrasana, and R. Piques, "A multi-scale analysis of the microstructure and the tensile mechanical behaviour of polyamide 66 fibre," Polymer, vol. 47, no. 1, pp. 367-378, 2006.

[27] N. Dencheva, Z. Denchev, M. J. Oliveira, and S. S. Funari, "Relationship between crystalline structure and mechanical behavior in isotropic and oriented polyamide 6," Journal of Applied Polymer Science, vol. 103, no. 4, pp. 2242-2252, 2007.

[28] H. P. Klug and L. E. Alexander, X-Ray Diffraction Procedures for Polycrystalline and Amorphous Materials, John Wiley \& Sons, New York, NY, USA, 2nd edition, 1974.

[29] L. M. Guerrini, M. C. Branciforti, T. Canova, and R. E. S. Bretas, "Electrospinning and characterization of polyamide 66 nanofibers with different molecular weights," Materials Research, vol. 12, no. 2, pp. 181-190, 2009.

[30] J. Coates, "Interpretation of infrared spectra, a practical approach," in Encyclopedia of Analytical Chemistry, R. A. Meyers, Ed., pp. 1-22, John Wiley \& Sons, New York, NY, USA, 2000.

[31] J. Charles, G. R. Ramkumaar, S. Azhagiri, and S. E. Gunasekaran, "FTIR and thermal studies on nylon-66 and $30 \%$ glass fibre reinforced nylon-66," Journal of Chemistry, vol. 6, no. 1, pp. 23-33, 2009.

[32] T. Ishisue, M. Okamoto, and K. Tashiro, "Real-time investigation of crystallization in nylon 6-clay nano-composite probed by infrared spectroscopy," Polymer, vol. 51, pp. 5585-5591, 2010.

[33] C. Caamaño, B. Grady, and D. E. Resasco, "Influence of nanotube characteristics on electrical and thermal properties of MWCNT/polyamide 6, 6 composites prepared by melt mixing," Carbon, vol. 50, no. 10, pp. 3694-3707, 2012.

[34] J. K. W. Sandler, S. Pegel, M. Cadek et al., "A comparative study of melt spun polyamide-12 fibres reinforced with carbon nanotubes and nanofibres," Polymer, vol. 45, no. 6, pp. 20012015, 2004

[35] C. I. Ferreira, C. Dal Castel, M. A. S. Oviedo, and R. S. Mauler, "Isothermal and non-isothermal crystallization kinetics of polypropylene/exfoliated graphite nanocomposites," Thermochimica Acta, vol. 553, pp. 40-48, 2013.

[36] S. Kumar, T. Rath, R. N. Mahaling, and C. K. Das, "Processing and characterization of carbon nanofiber/syndiotactic polystyrene composites in the absence and presence of liquid crystalline polymer," Composites A, vol. 38, no. 5, pp. 1304-1317, 2007.

[37] F. C. Chiu and G. F. Kao, "Polyamide 46/multi-walled carbon nanotube nanocomposites with enhanced thermal, electrical, and mechanical properties," Composites Part: A, vol. 43, pp. 208-218, 2012.

[38] F. C. Chiu and I. N. Huang, "Phase morphology and enhanced thermal/mechanical properties of polyamide 46/graphene 
oxide nanocomposites," Polymer Testing, vol. 31, pp. 953-962, 2012.

[39] H. Meng, G. X. Sui, P. F. Fang, and R. Yang, "Effects of acid- and diamine-modified MWNTs on the mechanical properties and crystallization behavior of polyamide 6," Polymer, vol. 49, no. 2, pp. 610-620, 2008.

[40] J. Li, L. Tong, Z. Fang, A. Gu, and Z. Xu, "Thermal degradation behavior of multi-walled carbon nanotubes/polyamide 6 composites," Polymer Degradation and Stability, vol. 91, no. 9, pp. 2046-2052, 2006.

[41] R. K. Layek, S. Samanta, D. P. Chatterjee, and A. K. Nandi, "Physical and mechanical properties of poly(methyl methacrylate) functionalized graphene/poly(vinylidine fluoride) nanocomposites: piezoelectric $\beta$-polymorph formation," Polymer, vol. 51, pp. 5846-5856, 2010.

[42] S. Vadukumpully, J. Paul, N. Mahanta, and S. Valiyaveettil, "Flexible conductive graphene/poly(vinyl chloride) composite thin films with high mechanical strength and thermal stability," Carbon, vol. 49, no. 1, pp. 198-205, 2011.

[43] H. Deng, E. Bilotti, R. Zhang et al., "Improving tensile strength and toughness of melt processed polyamide 6/multiwalled carbon nanotube composites by in situ polymerization and filler surface functionalisation," Journal of Applied Polymer Science, vol. 120, no. 1, pp. 133-140, 2011.

[44] J. Liu, A. Rasheed, M. L. Minus, and S. Kumar, "Processing and properties of carbon nanotube/ poly (methyl methacrylate) composite films," Journal of Applied Polymer Science, vol. 112, no. 1, pp. 142-156, 2009.

[45] M. Cai, D. Thorpe, D. H. Adamson, and H. C. Schniepp, "Methods of graphite exfoliation," Journal of Materials Chemistry, vol. 22, pp. 24992-25002, 2012.

[46] Y. Mao, S. Wen, Y. Chen et al., "High performance graphene oxide based rubber composites," Scientific Reports, vol. 3, article 2508, 2013.

[47] D. Cai and M. Song, "Recent advance in functionalized graphene/polymer nanocomposites," Journal of Materials Chemistry, vol. 20, pp. 7906-7915, 2010. 

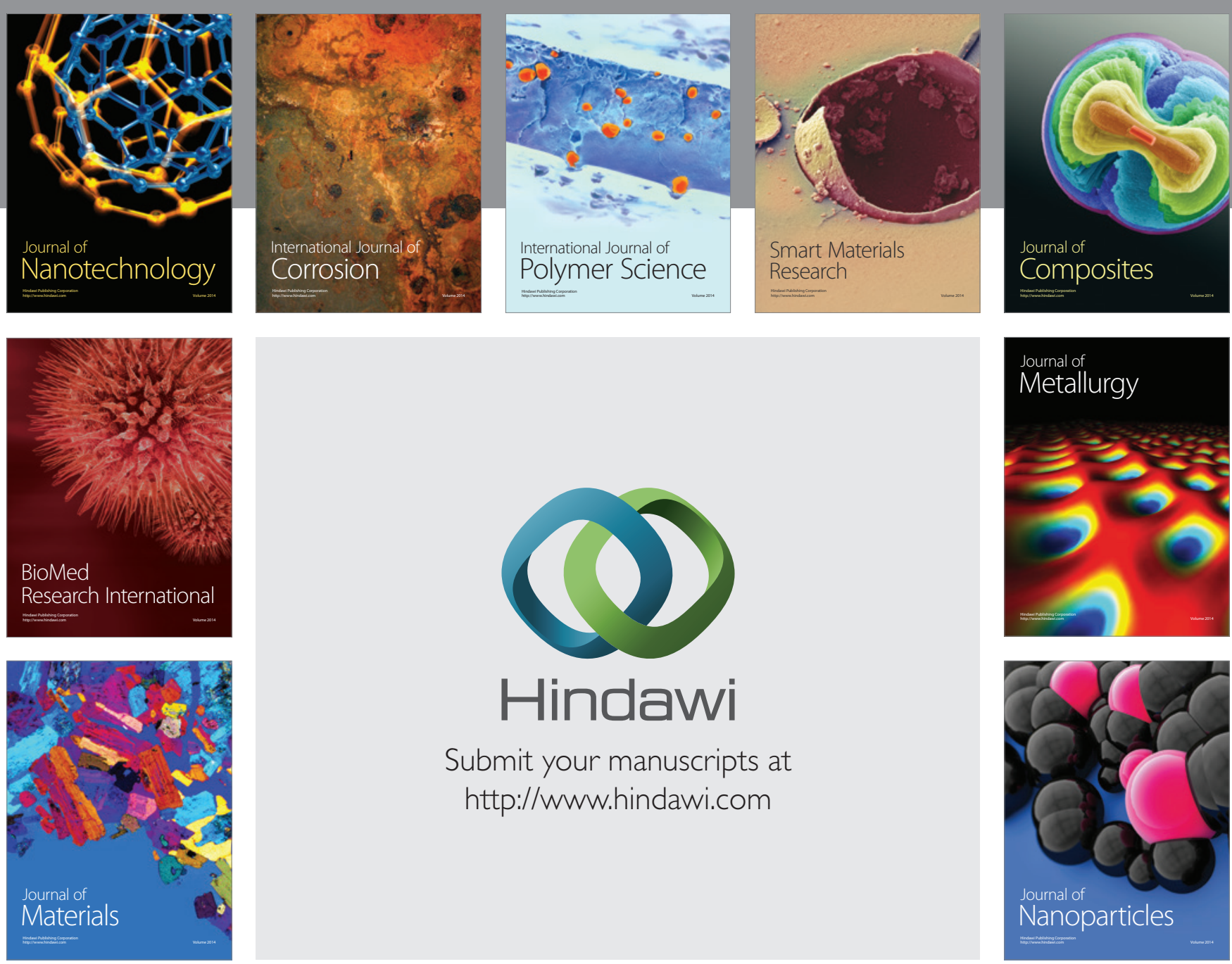

Submit your manuscripts at http://www.hindawi.com
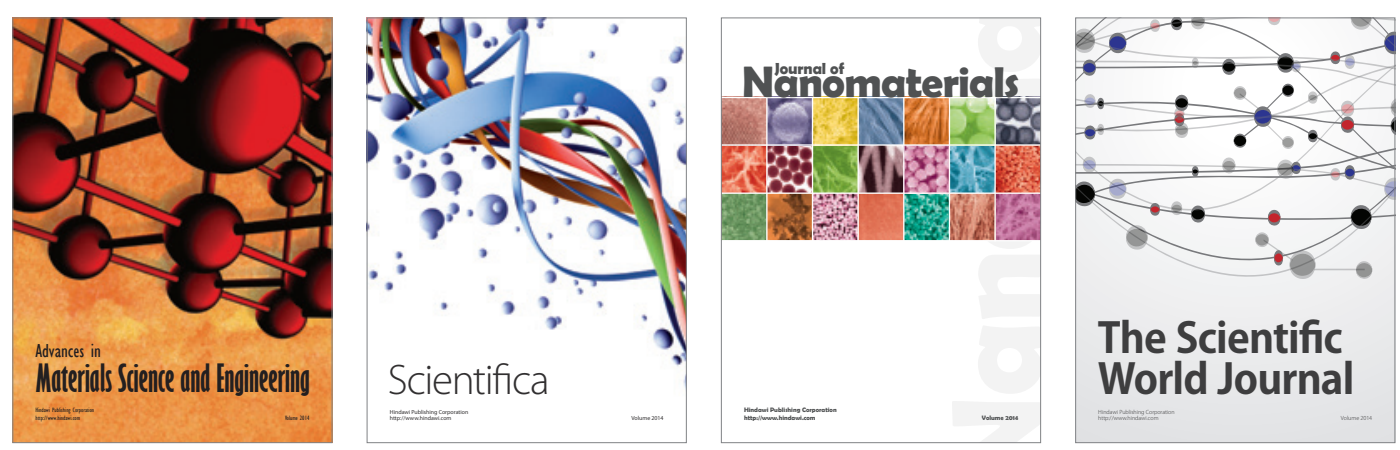

\section{The Scientific World Journal}
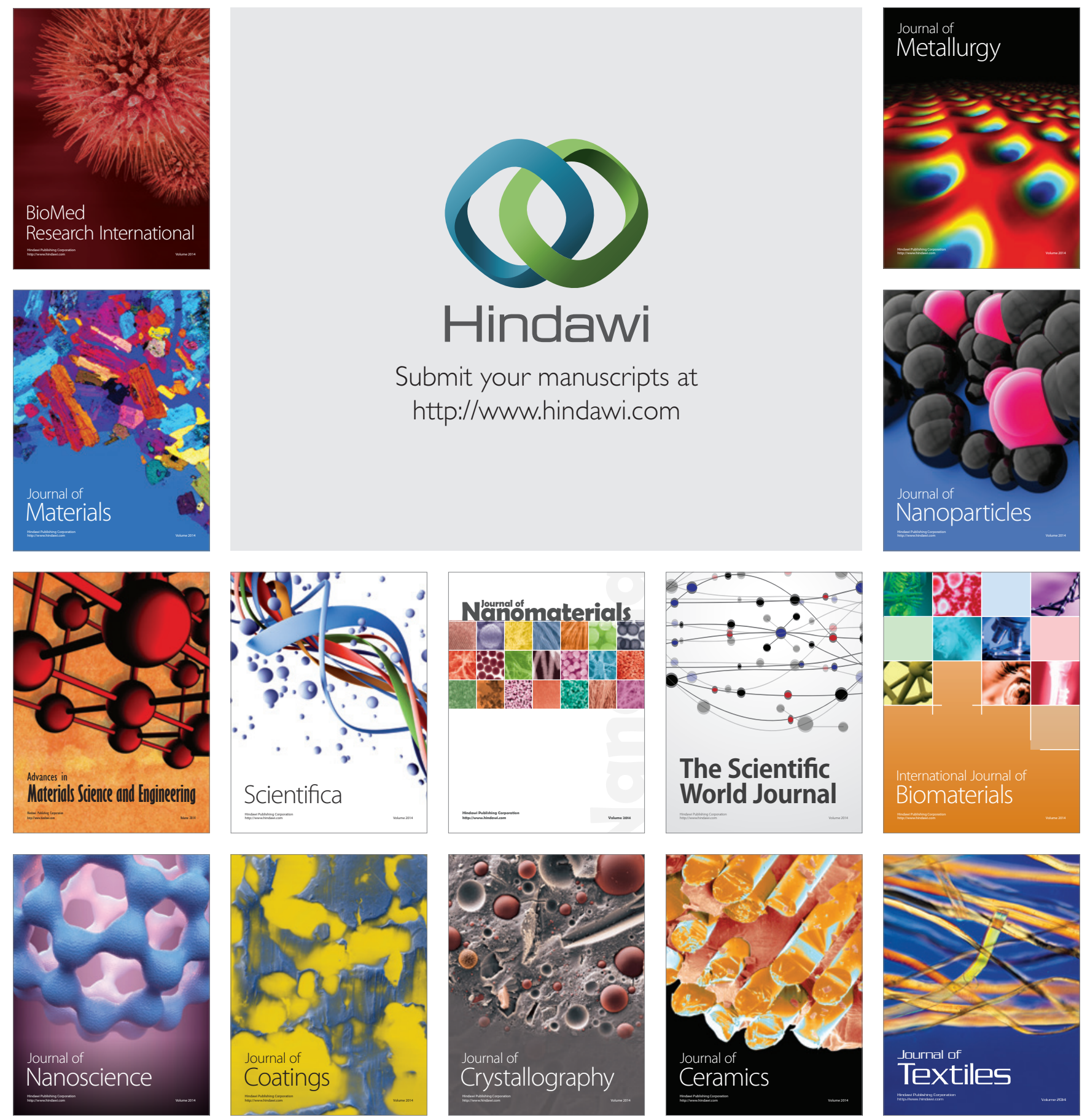